\title{
Impact of ligand protonation on higher-order metal complexation kinetics in aqueous systems
}

Raewyn M. Town and Herman P. van Leeuwen

\section{Supporting Information: Computation of $\mathbf{K}^{\mathrm{os}}$}

For computation of $K^{\text {os }}$ we follow the differentiated approach for multidentate ligands containing several charged sites. ${ }^{1}$ In brief, the value of $K^{\mathrm{os}}$ is usually estimated on the basis of the Fuoss equation, ${ }^{2}$ combined with Debye-Hückel electrostatics for the point charge interaction with inclusion of screening by the surrounding electrolyte solution: ${ }^{3}$

$K^{\mathrm{os}}=\frac{4 \pi}{3} N_{\mathrm{Av}} a_{g}^{3} \exp \left(-U^{\mathrm{os}} / k T\right)$

where $a_{\mathrm{g}}$ is the geometrical center-to-center distance between $\mathrm{M}$ and $\mathrm{L}$, and $U^{\mathrm{os}}$ represents the interionic potential for a single pair, which in the case of a composite ligand, L, composed of sites carrying different charges, sums all the electrostatic interactions between the central metal ion and the charges on L, i.e.

$U^{\mathrm{os}}=\frac{z_{\mathrm{M}} e^{2}}{4 \pi \varepsilon_{0} \varepsilon} \sum_{i}^{n} \frac{z_{i}}{a_{i}}\left[1-\frac{\kappa a_{i}}{1+\kappa a_{i}}\right]$

where $z_{\mathrm{M}}$ is the charge number of the central metal ion, $z_{i}$ is the charge number of site $i, n$ the total number of charged sites on the ligand $\mathrm{L}$, and $a_{i}$ the charge center-to-center distance between $i$ and $\mathrm{M}$. The screening factor $\kappa a_{i} /\left(1+\kappa a_{i}\right)$ varies from one site to another with varying $a_{i}, \varepsilon_{0} \varepsilon$ is the permittivity of the electrolyte solution, and $\kappa$ is the reciprocal Debye length of the electrolyte solution, defined by:

$\kappa^{2}=e^{2} \sum_{i} z_{i}^{2} c_{i} N_{\mathrm{Av}} / \varepsilon_{0} \varepsilon k T$

where all symbols have their usual meaning.

The effective charge number $\hat{z}_{\mathrm{L}}$ for the complete ligand is defined as:

$$
\hat{z}_{\mathrm{L}}=a^{\mathrm{os}} \sum_{i}^{n} \frac{z_{i}}{a_{i}}\left[1-\frac{\kappa a_{i}}{1+\kappa a_{i}}\right]
$$


where $a^{\text {os }}$ is the charge center-to-center distance between the primary outer-sphere bound sites and M.

\section{Cd(II)/pyridine-2,6-dicarboxylic acid (PDCA, $\left.\mathrm{C}_{5} \mathrm{H}_{3} \mathrm{~N}(\mathrm{COOH})_{2}\right)$}

In the outer-sphere complexes, the center-to-center distances were taken as $0.45 \mathrm{~nm}$ between $\mathrm{Cd}^{2+}$ and the negatively charged carboxyl groups, $0.45 \mathrm{~nm}$ between the $\mathrm{Cd}^{2+}$ and the positively charged $\mathrm{NH}^{+}$in $\mathrm{HL}^{-}$. The intra-ligand separation of the carboxyl groups was estimated as $0.90 \mathrm{~nm}$ in the free ligand and $0.65 \mathrm{~nm}$ in the outer-sphere complex. In a $1: 1$ electrolyte of concentration $0.1 \mathrm{~mol} \mathrm{dm}^{-3}, \kappa=1 \mathrm{~nm}^{-1}$.

\section{$\underline{\text { ML precursor outer-sphere complexes }}$}

(a) $\mathrm{M}\left(\mathrm{H}_{2} \mathrm{O}\right)_{6} \cdot \mathrm{L}$. For $\mathrm{L}^{2-}$ as the outer-sphere ligand, the $\mathrm{N}$ carries no charge and hence its position does not matter. The most favourable ion pair is obtained with both carboxylates in the outer-sphere of M. The various terms to be considered are (i) attraction between $M$ and the two incoming carboxylates, and (ii) the change in intra-ligand repulsion in the incoming ligand. Accordingly $U^{\mathrm{os}}=1.8 \times 10^{-20} \mathrm{~J}$, giving a $K^{\mathrm{os}}=20 \mathrm{dm}^{3} \mathrm{~mol}^{-1}$ and $\hat{z}_{\mathrm{L}}=-1.3$.

(b) $\mathrm{M}\left(\mathrm{H}_{2} \mathrm{O}\right)_{6} \cdot \mathrm{HL}^{+}$. For $\mathrm{HL}^{-}$as the outer-sphere ligand, the $\mathrm{N}$ is protonated, i.e. there are two negative carboxylates and one positive $\mathrm{NH}^{+}$group. The terms involved are (i) attraction between $\mathrm{M}^{2+}$ and the two incoming carboxylates, and (ii) the change in intra-ligand repulsion in the incoming ligand, and (iii) repulsion between $\mathrm{M}^{2+}$ and $\mathrm{NH}^{+}$. In this we obtain $U^{\mathrm{os}}=8.9 \times 10^{-21} \mathrm{~J}$, giving $K^{\mathrm{os}}=2 \mathrm{dm}^{3} \mathrm{~mol}^{-1}$ and $\hat{z}_{\mathrm{L}}=-0.65$.

\section{$\underline{\mathrm{ML}_{2}}$ precursor outer-sphere complexes}

For this case, we consider the composite ion pair between the inner-sphere $\mathrm{ML}^{0}$ and the incoming ligand. Ignoring the small change in inter-ligand repulsion, this means that $K^{\mathrm{os}}$ corresponds to the $z_{\mathrm{M}} z_{\mathrm{L}}$ $=0$ case, i.e. $K^{\mathrm{os}}=0.32{ }^{4}$ 


\section{$\mathrm{Ni}(\mathrm{II}) / \mathrm{N}, \mathrm{N}$-bis(2-hydroxyethyl)glycine (bicine, $\left.\left(\mathrm{HOCH}_{2} \mathrm{CH}_{2}\right)_{2} \mathrm{NCH}_{2} \mathrm{COOH}\right)$}

The center-to-center distances were taken as $0.45 \mathrm{~nm}$ between $\mathrm{Cd}^{2+}$ and both the carboxyl group and the amino group.

\section{ML precursor outer-sphere complexes}

(a) $\mathrm{M}\left(\mathrm{H}_{2} \mathrm{O}\right)_{6} \cdot \mathrm{L}^{+}$. For $\mathrm{L}^{-}$as the outer-sphere ligand, the term to consider is attraction between $\mathrm{M}^{2+}$ and the negatively charged carboxyl group. This gives $U^{\mathrm{os}}=9.4 \times 10^{-21} \mathrm{~J}, K^{\mathrm{os}}=2.4 \mathrm{dm}^{3} \mathrm{~mol}^{-1}$ and $\hat{z}_{\mathrm{L}}=$ -0.69 .

(b) $\mathrm{M}\left(\mathrm{H}_{2} \mathrm{O}\right)_{6} \cdot \mathrm{HL}^{2+}$. In this case we have attraction between $\mathrm{M}^{2+}$ and $\mathrm{COO}^{-}$and repulsion of the same magnitude between $\mathrm{M}^{2+}$ and $\mathrm{NH}^{+}$. Accordingly, this is analogous to the $z_{\mathrm{M}} z_{\mathrm{L}}=0$ case, i.e. $K^{\mathrm{os}}=0.32$.

\section{$\underline{\mathrm{ML}}_{2}$ precursor outer-sphere complexes}

For this case, we consider the composite ion pair between the inner-sphere $\mathrm{ML}^{+}$and the incoming ligand.

(a) $\mathrm{ML}\left(\mathrm{H}_{2} \mathrm{O}\right)_{5} \mathrm{~L} \cdot \mathrm{L}$. The interaction to consider is attraction between the $\mathrm{ML}^{+}$and the incoming $\mathrm{COO}^{-}$. This gives $U^{\mathrm{os}}=4.7 \times 10^{-21} \mathrm{~J}, K^{\mathrm{os}}=0.7 \mathrm{dm}^{3} \mathrm{~mol}^{-1}$, and $\hat{z}_{\mathrm{L}}=-0.35$.

(b) $\mathrm{ML}\left(\mathrm{H}_{2} \mathrm{O}\right)_{5} \mathrm{~L} \cdot \mathrm{HL}^{+}$. Here we have attraction between $\mathrm{ML}^{+}$and $\mathrm{COO}^{-}$and repulsion of the same magnitude between $\mathrm{ML}^{+}$and $\mathrm{NH}^{+}$. Accordingly, this is analogous to the $z_{\mathrm{M}} z_{\mathrm{L}}=0$ case, i.e. $K^{\mathrm{os}}=0.32$. 


\section{References}

(1) van Leeuwen, H. P.; Town, R. M.; Buffle, J. J. Phys. Chem. A 2007, 111, 2115

(2) Fuoss, R. J. Am. Chem. Soc. 1958, 80, 5059.

(3) Lyklema, J. Fundamentals of Interface and Colloid Science. Vol. 1. Fundamentals. Academic Press: London, 1991.

(4) Morel, F.M.M.; Hering, J.G. Principles and Applications of Aquatic Chemistry; Wiley: New York 1993 